\title{
Youths' Knowledge and Perceptions of Health Risks Associated With Unprotected Oral Sex
}

\author{
Arianna Strome ${ }^{1 *}$ \\ $N^{\prime}$ dea Moore-Petinak, MSc ${ }^{2 *}$ \\ Marika Waselewski, MPH \\ Tammy Chang, MD, MPH, MS ${ }^{3}$ \\ *These authors contributed equally as co- \\ first authors. \\ 'University of Michigan Medical School, \\ University of Michigan, Ann Arbor, Michigan \\ ${ }^{2}$ School of Public Health, University of Mich- \\ igan, Ann Arbor, Michigan \\ ${ }^{3}$ Department of Family Medicine, University \\ of Michigan, Ann Arbor, Michigan
}

Conflicts of interest: authors report none.

\section{CORRESPONDING AUTHOR}

Tammy Chang

University of Michigan

Department of Family Medicine

2800 Plymouth Road

Building 14 G128

Ann Arbor, MI 48109

tachang@med.umich.edu

\begin{abstract}
PURPOSE Although rates of sexually transmitted infections (STIs) and human papillomavirus (HPV)-related head and neck cancers associated with oral sex are increasing, less than 10\% of youths report using protection. This study aims to assess youths' knowledge and perceptions of oral sex risk and barriers to protection use.
\end{abstract}

METHODS Our study uses MyVoice, a national text message poll of youths aged 14-24 years. Four open-ended probes were fielded to 1,215 youths in March 2019. Qualitative data were analyzed using thematic analysis and quantitative data were summarized with descriptive statistics.

RESULTS Nine hundred and nine youths responded to the survey (relative risk $[R R]=74.8 \%$ ). Youths' responses regarding why protection is frequently not used centered around: lack of education (22.4\%), no perceived STI risk (19.8\%), decreased pleasure (19.3\%), and no pregnancy risk (15.7\%). Youths believed that comprehensive education (53.7\%), normalization in popular culture and media (19.1\%), increased access to protection (15\%), and improved protection options (10.5\%) would increase protection use during oral sex.

CONCLUSION Youths demonstrated limited knowledge of the risks of oral sex, dissatisfaction with current protection options, and a need for normalization in popular culture. Programs developed with youths in mind may be able to successfully increase protection use and decrease rates of STI transmission and oral sex-related HPV head and neck cancer.

\section{VISUAL ABSTRACT}

Ann Fam Med 2022;20:72-26. https://doi.org/10.1370/afm.2761.

\section{INTRODUCTION}

$\mathrm{R}$ ates of sexually transmitted infections (STIs) in the United States have increased for 5 consecutive years. ${ }^{1}$ Transmission rates of Chlamydia trachomatis, Neisseria gonorrhoeae, and syphilis are at their highest recorded, with 2.5 million cases diagnosed annually. ${ }^{1,2}$ Youths (aged 15-24 years) are disproportionately affected by STIs, accounting for approximately one-half of STI incidence, with an estimated 1 in 4 sexually active adolescent females currently having an STI.

Adolescents are a uniquely vulnerable population for STI risk. Many factors that increase youths' risk of STI transmission have been previously described, including initiation of sex at a younger age, multiple sex partners, failure to use barrier protection, cervical ectopy, mental health issues, substance abuse, and limited access to health care. ${ }^{3,4}$ Cognitively, youths have increased activation of the reward-sensitivity regions of their brains, and are more likely to engage in sensation-seeking behaviors and risk taking. ${ }^{5}$ Additionally, it has been shown that many health care clinicians fail to assess adolescents' risky sexual behaviors and sexually transmitted disease (STD) risk, ${ }^{6}$ and youths are less likely to seek health care, resulting in lower rates of diagnosis and treatment. ${ }^{6,7}$

Research on adolescent sexual behavior and STIs has predominantly focused on prevention and interventions for reduced transmission via vaginal intercourse, rather than other forms of sexual activities, such as oral sex. ${ }^{8,9}$ Although the risk of STI transmission is lower for oral sex than vaginal sex, many STIs are transmitted orally, including herpes, gonorrhea, chlamydia, syphilis, and HIV, as well as other respiratory pathogens. ${ }^{9-11}$ Additionally, due to the general perception that oral sex is less risky, there is potential for increased STI transmission via oral sex resulting from this belief and subsequent lack of the use of protection. ${ }^{9}$ According to the Centers for 
Disease Control and Prevention (CDC), 85\% of sexually active adults (aged 18-44 years) and 33\% of adolescents (aged 15-17 years) have engaged in oral sex at least 1 time..$^{10,12}$ Between $14 \%$ and $50 \%$ of youths also have oral sex before any other experiences with sexual intercourse. ${ }^{9}$ Yet studies show only $7 \%$ to $10 \%$ of youths report using protection during oral sex..$^{10,12,13}$

A further concern of unprotected oral sex is the risk of oral human papillomavirus (HPV) infection, which can lead to oropharyngeal squamous cell carcinoma (OPSCC). ${ }^{14}$ In the past 20 years, the rate of HPV positive OPSCC went from $20 \%$ to $70 \%$ in the United States. ${ }^{15,16}$ Additionally, in recent surveillance data, HPV-related head and neck cancers have surpassed HPV-related cervical cancers. ${ }^{17}$ Various behaviors have been shown to increase risk of HPV-infection including engaging in oral sex, a greater number of oral sex partners, and having a female partner with a history of cervical cancer. ${ }^{18-20}$ The HPV vaccine is effective against vaccine-type strains but there is a low vaccination rate, particularly among men, so the effect of the vaccine on the population as a whole may be low. ${ }^{21}$ Additionally, there are limited studies evaluating HPV vaccine effectiveness against oral HPV infection. ${ }^{22}$ Due to this rapid increase of HPV-related OPSCC and limited vaccination uptake, it is necessary to better understand youths' behavior in order to prevent infection. ${ }^{14}$

There is no recent data about youths' knowledge and behaviors regarding oral sex or perceptions of protection usage, as previous studies were published over a decade ago, ${ }^{9,23}$ There is a critical need to understand what a contemporary sample of youths knows about oral sex and its associated risks, as well as what the barriers are to using protection. This study aims to answer these important questions. Understanding of these behaviors can be used to inform effective, youth-centered interventions to decrease transmission of STIs through oral sex and decrease rates of HPV head and neck cancer.

\section{METHODS}

Our study uses MyVoice (www.hearmyvoicenow.org), a national open-ended text message poll of youths aged 14-24 years. Enrolled participants must have access to a cellular device with text-messaging capabilities and are sent weekly questions via text message. Participants are recruited through Instagram, Facebook, and in-person community events to meet national benchmarks based on the American Community Survey. The study was approved by the University of Michigan Institutional Review Board (HUM00119982). To ensure equitable enrollment and because the study was deemed of minimal risk, parental consent is waived for minors.

Questions were iteratively developed with a team of researchers, physicians, and youths, and 4 open-ended probes were sent to participants:

(1) A recent study showed that very few youths use protection (condoms/dental dams) during oral sex. Why do you think this is? (2) On a scale of 1 to 5 , how risky do you think it is to have oral sex without protection? (1-Not risky at all, 5-Very risky), (3) What do you think are the risks (if any) to not using protection during oral sex? and (4) What might help more people use protection during oral sex?

Two investigators reviewed responses to identify thematic codes and create a codebook based on themes that emerged. Each response was coded by 2 independent investigators and discussed until consensus was reached. Responses unrelated to the question were excluded from coding. Demographic information was collected at study enrollment and summarized using descriptive statistics. Response data was stratified by gender (female, male, and "other" gender) and differences were assessed with $\mathrm{c}^{2}$ tests.

\section{RESULTS}

Of the 1,215 MyVoice participants, 909 responded to the survey $(74.8 \%)$. Respondents had a mean age of 18.9 years (SD 2.9). Most respondents identified as female (58.7\%) and nonHispanic White (58.1\%). Nearly one-half of the respondents were from the Midwest (44.7\%) and one-third received high school free or reduced lunch (33.7\%). Additional demographic characteristics of respondents are summarized in Table 1.

In the first question, respondents most commonly attributed the lack of protection use during oral sex to minimal or an absence of education about the subject $(200 / 893 ; 22.4 \%)$. Particularly, they noted a lack of education on the risks of unprotected oral sex, as well as limited information about oral sex protection methods; stating protection usage during oral sex "is not something I have been taught about." Many youths $(177 / 893 ; 19.8 \%)$ also noted that they "don't think many kids know that you can get STIs from oral." Youths also mentioned lack of pleasure as a reason for not using protection stating they are uncomfortable, don't feel good, and don't taste good " "it's more pleasurable without the condom" $(172 / 893 ; 19.3 \%)$. Some respondents expressed a lesser concern for STIs compared with pregnancy as the reason for not using protection during oral sex, "I think that youths are more concerned about getting pregnant than contracting an STD, so they aren't as careful about using protection for oral sex" $(140 / 893 ; 15.7 \%)$. Some respondents additionally mentioned trouble with accessing protection due to embarrassment when purchasing, inadequate funds, and not "know[ing] where to get them" $(104,11.6 \%)$. When stratifying the data by gender identity, females more commonly attributed lack of protection usage to educational deficiencies than male respondents ( $26.7 \%$ vs $14.2 \% ; P=0.0001)$. Table 2 presents the most frequently identified thematic codes with representative quotes.

On a scale from 1 (not risky at all) to 5 (very risky), nearly one-third of youth respondents ranked the risk of unprotected oral sex as a $3(269 / 883 ; 30.5 \%)$. Fewer respondents $(72 / 883 ; 8.2 \%)$ rated unprotected oral sex as a 1 , not at all risky, compared with a 5 , very risky $(178 / 883 ; 20.2 \%)$. Female respondents were more likely to rank the risk of oral sex as 4-5 compared with male respondents (females $42.8 \%$ vs males 
$21.7 \%$ ), while male respondents were more likely to rank risk as 1-2 compared with female respondents (males $46.3 \%$ vs females $23.4 \%$ ). When asked about the main risks of not using protection during oral sex, the vast majority of respondents noted the greatest risk to be acquisition of STIs (760/864; 88.0\%). STD risk was the most common perceived risk across all gender groups (females $89 \%$ vs males $85.4 \%$ vs other $95.2 \%$ ). Notably, a small percentage of youths stated that the main risk is pregnancy, "unwanted pregnancies" (36/864, 4.2\%). Of the youths that believed unprotected oral sex is not risky, their rationale included an inability to get pregnant, a reduced risk of transmission when you know your partner, and an increased difficulty in transmission of STIs through oral sex.

\section{Table 1. Demographic Characteristics of Poll Respondents}

\begin{tabular}{|c|c|}
\hline & $n(\%), n=909^{a}$ \\
\hline Age, y, mean (SD) & $18.9(2.9)$ \\
\hline $14-17, \mathrm{n}(\%)$ & $380(41.8)$ \\
\hline $18-24$ & $529(58.2)$ \\
\hline \multicolumn{2}{|l|}{ Gender, n (\%) } \\
\hline Male & 307 (33.8) \\
\hline Female & $533(58.7)$ \\
\hline Other & $68(7.5)$ \\
\hline \multicolumn{2}{|l|}{ Race/Ethnicity, n (\%) } \\
\hline Non-Hispanic White & $528(58.1)$ \\
\hline Non-Hispanic Black & $82(9.0)$ \\
\hline Hispanic & $111(12.2)$ \\
\hline Non-Hispanic Other & $187(20.6)$ \\
\hline \multicolumn{2}{|l|}{ Education, n (\%) } \\
\hline$<$ High school & $463(51)$ \\
\hline High school graduate & $79(8.7)$ \\
\hline Some college or tech school & $235(25.9)$ \\
\hline Associate's or tech graduate & $32(3.5)$ \\
\hline$\geq$ Bachelor's degree & $99(10.9)$ \\
\hline \multicolumn{2}{|l|}{ Parent education, $\mathrm{n}(\%)$} \\
\hline$\leq$ High school & $127(14.0)$ \\
\hline Some college or tech school & $102(11.2)$ \\
\hline Associate's or tech graduate & $76(8.4)$ \\
\hline Bachelor's degree & $253(27.9)$ \\
\hline Master's degree & $241(26.5)$ \\
\hline Doctoral degree & $109(12.0)$ \\
\hline \multicolumn{2}{|l|}{ HS free lunch $(n=901), n(\%)$} \\
\hline Yes & $304(33.7)$ \\
\hline No & $597(66.3)$ \\
\hline \multicolumn{2}{|l|}{ Region $(n=901), n(\%)$} \\
\hline West & $162(18.0)$ \\
\hline Midwest & $403(44.7)$ \\
\hline South & $215(23.9)$ \\
\hline Northeast & $121(13.4)$ \\
\hline
\end{tabular}

When prompted about what youths thought may help people use protection more during oral sex, over one-half $(459 / 855,53.7 \%)$ reported that better education could improve the use of protection during oral sex. These responses suggested a need for "more actual sex education," modification of education methods by "talking about safe sex vs saying don't have sex," and improved "awareness." Youths also mentioned normalization of talking about oral sex as a method for improving protection usage (163/855; 19.1\%). Respondents suggested, "less of a taboo around talking about sex," "spreading the word," and "the stigma behind it would have to be broken before anything can help" as examples of how normalization may occur. Some respondents also mentioned that reducing barriers through "cheaper and easier access," free access to protection in clinics and schools, and minimizing interaction required to access protection to lessen embarrassment could improve access and use (128/855; $15.0 \%)$. Youths additionally suggested having increased and improved options for protection like more natural feeling "thinner condoms," and improved taste (90/855; 10.5\%).

\section{DISCUSSION}

Many findings from our study are aligned with studies of youths from over a decade ago which found that teens have oral sex for physical pleasure and a reduced risk when compared with vaginal sex. ${ }^{23}$ Our study adds to this literature, however, by describing reasons reported by a large contemporary sample of youths on the barriers to engaging in oral sex with protection, including a lack of knowledge of the risks, limited access to and dissatisfaction with protection methods, and cultural norms. Many respondents knew that some STIs can be transmitted through unprotected oral sex, but many youths also underestimated the severity of risk associated with the act, "You can't really get anything super harmful from it." A lack of inclusive, comprehensive sexual education, as well as the lack of safe sexual practices depicted in popular culture and media were salient themes that respondents associated with low levels of protection use, "I think it's a combination of poor sex education and the taboo around sex."

Overall, youths were underinformed about the extent of risk associated with unprotected oral sex. While most youths acknowledged that STIs are a risk associated with oral sex $(88.1 \%)$, many respondents $(60.1 \%)$ reported a low-to-moderate risk (risk score of 1-3) associated with unprotected oral sex. While the evidence may at first seem contradictory, these results suggest that youths may believe STIs are transmissible through oral sex, but the severity and transmissibility of those STIs are not as high as through vaginal sex, thus making the act "less risky." Youths explained that they also perceived oral sex as less risky because, unlike vaginal sex, it does not result in pregnancy. Although pregnancy may be the primary concern of many youths, education on the risks associated with various sexual acts should stress the importance of using protection in all behaviors to reduce the risk of STIs. 
Table 2. Questions, Themes, and Example Participant Quotes

\begin{tabular}{|c|c|c|c|c|}
\hline Question, Theme ${ }^{a}$ & All n (\%) & Female n (\%) & Male n (\%) & Example Participant Quote \\
\hline No perceived STI risk & $177(19.8)$ & $109(20.9)$ & $52(17.2)$ & "Because they don't think they can get stds from oral" \\
\hline Sensation/pleasure & $172(19.3)$ & $95(18.2)$ & $66(21.8)$ & "I think they think that condoms will result in a loss of pleasure" \\
\hline Access/cost & $104(11.6)$ & $58(11.1)$ & $32(10.6)$ & $\begin{array}{l}\text { "They probably don't because it's either too expensive or they feel } \\
\text { weird buying these items" }\end{array}$ \\
\hline Q2: On a scale of 1 & 5, how ris & $y$ do you think & it is to have o & al sex without protection? $(n=883)$ \\
\hline 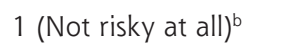 & $72(8.2)$ & $26(5.0)$ & $42(14.3)$ & "1 because fertilization is never actually achieved, it is just for pleasure" \\
\hline $4^{b}$ & $136(15.4)$ & $100(19.1)$ & $28(9.5)$ & "4 You don't know what disease someone could have" \\
\hline 5 (Very risky) $^{b}$ & $178(20.2)$ & $124(23.7)$ & $36(12.2)$ & "5 STIs can be extremely serious and easily transferred" \\
\hline Q3: What do you th & $k$ are the ri & ks (if any) to no & t using protec & tion during oral sex? $(n=864)$ \\
\hline STIs/diseases & $760(88.0)$ & $455(89.0)$ & $245(85.4)$ & "You could get a disease/infection like with any other type of sex." \\
\hline Seems not riskyb & $49(5.7)$ & $16(3.1)$ & $31(10.8)$ & $\begin{array}{l}\text { "...there aren't as many risks by not using protection because it } \\
\text { doesn't involve the danger of getting someone pregnant" }\end{array}$ \\
\hline Q4: What might hel & more peop & use protectio & during oral s & $x ?(n=855)$ \\
\hline Better education ${ }^{b}$ & $459(53.7)$ & $293(58.3)$ & $129(45.4)$ & $\begin{array}{l}\text { "It may help to have some more education about the consequences of } \\
\text { oral sex without protection." }\end{array}$ \\
\hline
\end{tabular}

Youths in our study also stated that additional sexual education could bring awareness to the need for oral sex protection. Previous evaluations of comprehensive sexual education programs (compared with abstinence-only education) show that condom and contraceptive use can increase nearly $50 \%$ for those that participate. ${ }^{24}$ Including more explanation of the risks associated with oral sex, such as STIs and HPV-related cancers, may result in a similar increase in protection use during oral sex. Also, educators may need to focus on correcting misinformation; a small group of our study youths believe they can get pregnant from oral sex. Educators should also ensure that material is inclusive of all sexualities; respondents in our survey explained that female-centered options, such as dental damns, were not taught in their sexual education programs.

Long-term efforts to increase STI protection use during oral sex will need to focus on changing cultural norms and widening the types of contraception that are available. Youths in our survey frequently mentioned the lack of protection use in film, television, online, and wider popular culture. This lack of responsible representation of sexual acts has an impact on youths' behaviors, as sexual norms for many teens are shaped through exposure to media more than by their parents or traditional education. ${ }^{25}$ In fact, one-half of teens do not feel comfortable talking to their parents about sex, which gives insight into why youths feel the need to seek sexual information from other sources. ${ }^{26}$ Respondents also stated that the types of protection available for oral sex-namely, condoms and dental dams-are not desirable due to their reduction of pleasure for the user or associated tastes. Future research should explore whether protection options can improve the user experience without sacrificing efficacy.

Our study is not without limitations. A text messagebased platform allows us to reach more youths across the country and retrieve more rapid responses on salient issues, but other research methods, such as focus groups and 
in-person interviews, may be able to provide deeper exploration of the themes identified. Although our study focuses on youths, parents and educators also play an invaluable role in the formation of youths' sexual norms. Further research should explore the barriers that may exist among these 2 groups in discussing protection during oral sex.

\section{CONCLUSION}

Youths in our survey demonstrated limited knowledge surrounding risks of oral sex without protection, dissatisfaction with current protection options, and a need for normalization in popular culture. These results suggest a continued need for more comprehensive and inclusive sex education that clearly explains the risks of unprotected oral sex, methods of protection, as well as increased depictions of safe sexual practices in popular media, and normalization of discussions on the topic. Programs and policies developed with the experiences and preferences of youths in mind may be more successful in increasing protection use and subsequently decreasing rates of STI transmission and HPV-related head and neck cancer.

\section{Read or post commentaries in response to this article.}

Key words: oral sex; adolescents; sexually transmitted infections; text message survey; sex

Submitted July 14, 2020; submitted, revised, May 19, 2021; accepted June 11, 2021.

Author contributions: M.W. and T.C. were involved in the design and conducting of the survey. N.M-P. and A.S. were involved in the coding of the data. M.W. performed the statistical analyses. N.M-P., A.S., M.W., and T.C. contributed to writing and revising the manuscript before submission.

Funding support: This research was funded by the Michigan Institute for Clinical \& Health Research, the University of Michigan MCubed program, and the University of Michigan Department of Family Medicine. These funders had no role in the design and conduct of the study; collection, management, analysis, and interpretation of the data; preparation, review, or approval of the manuscript; and decision to submit the manuscript for publication.

Previous presentation: Poster presented at the North American Primary Care Research Group 2019 Annual Meeting; November 16-20, 2019; Toronto, Ontario, Canada

Acknowledgments: We would like to thank Chloe Harper and Sasha Akuezue for their contribution to the study.

\section{References}

1. Bowen v, Braxton J, Davis D, et al. Sexually Transmitted Disease Surveillance 2018. Centers for Disease Control and Prevention; 2019. Accessed Jun 10, 2020. $10.15620 / c d c .79370$

2. Hook El, Bolan G, Fraser M, Harvey D. Telebriefing Transcript: 2018 STD Prevention Conference. NCHHSTP newsroom. Accessed Jun 10, 2020. https://www.cdc.gov/nchhstp/newsroom/2018/press-briefing-transcript2018-std-prevention-conf.html

3. Workowski KA, Bolan GA; Centers for Disease Control and Prevention. Sexually transmitted diseases treatment guidelines, 2015. MMWR Recomm Rep. 2015;64(RR-03):1-137.

4. Wangu Z, Burstein GR. Adolescent sexuality: updates to the sexually transmitted infection guidelines. Pediatr Clin North Am. 2017;64(2):389-411.
5. van Duijvenvoorde AC, Peters S, Braams BR, Crone EA. What motivates adolescents? Neural responses to rewards and their influence on adolescents' risk taking, learning, and cognitive control. Neurosci Biobehav Rev. 2016;70:135-147.

6. Shannon CL, Klausner JD. The growing epidemic of sexually transmitted infections in adolescents: a neglected population. Curr Opin Pediatr. 2018; 30(1):137-143. 10.1097/MOP.0000000000000578

7. Cuffe KM, Newton-Levinson A, Gift TL, McFarlane M, Leichliter JS. Sexually transmitted infection testing among adolescents and young adults in the United States. J Adolesc Health. 2016;58(5):512-519.

8. Lefkowitz ES, Vasilenko SA, Leavitt CE. Oral vs. vaginal sex experiences and consequences among first-year college students. Arch Sex Behav. 2016;45(2): 329-337. 10.1007/s10508-015-0654-6

9. Halpern-Felsher BL, Cornell JL, Kropp RY, Tschann JM. Adolescents and oral sex: perceptions, attitudes, and behavior. J Adolesc Health. 2005;36(2): 109-110.

10. Centers for Disease Control and Prevention. STD risk and oral sex - CDC fact sheet. Accessed June 10, 2020. https://www.cdc.gov/std/healthcomm/stdfactstdriskandoralsex.htm

11. Edwards S, Carne C. Oral sex and transmission of non-viral STIs. Sex Transm Infect. 1998;74(2):95-100. 10.1136/sti.74.2.95

12. Holway GV, Hernandez SM. Oral sex and condom use in a U.S. national sample of adolescents and young adults. J Adolesc Health. 2018;62(4):402410. 10.1016/j.jadohealth.2017.08.022

13. Habel MA, Leichliter JS, Dittus PJ, Spicknall IH, Aral SO. Heterosexual anal and oral sex in adolescents and adults in the United States, 2011-2015. Sex Transm Dis. 2018;45(12):775-782. 10.1097/OLQ.0000000000000889

14. Taberna M, Mena M, Pavón MA, Alemany L, Gillison ML, Mesía R. Human papillomavirus-related oropharyngeal cancer. Ann Oncol. 2017;28(10):23862398. 10.1093/annonc/mdx304

15. D'Souza G, McNeel TS, Fakhry C. Understanding personal risk of oropharyngeal cancer: risk-groups for oncogenic oral HPV infection and oropharyngeal cancer. Ann Oncol. 2017;28(12):3065-3069. 10.1093/annonc/mdx535

16. Sathish N, Wang X, Yuan Y. Human papillomavirus (HPV)-associated oral cancers and treatment strategies. J Dent Res. 2014;93(7)(Suppl):29S-36S.

17. Van Dyne EA, Henley SJ, Saraiya M, Thomas CC, Markowitz LE, Benard VB. Trends in human papillomavirus-associated cancers - United States, 1999 2015. MMWR Morb Mortal Wkly Rep. 2018;67(33):918-924.

18. Centers for Disease Control and Prevention. HPV and oropharyngeal cancer Accessed Jun 10, 2020. https://www.cdc.gov/cancer/hpv/basic_info/hpv_oropharyngeal.htm

19. Marur S, D'Souza G, Westra WH, Forastiere AA. HPV-associated head and neck cancer: a virus-related cancer epidemic. Lancet Oncol. 2010;11(8):781789. 10.1016/S1470-2045(10)70017-6

20. Chancellor JA, Ioannides SJ, Elwood JM. Oral and oropharyngeal cancer and the role of sexual behaviour: a systematic review. Community Dent Oral Epidemiol. 2017;45(1):20-34. 10.1111/cdoe.12255

21. Chaturvedi AK, Graubard BI, Broutian T, et al. Effect of prophylactic human papillomavirus (HPV) vaccination on oral HPV infections among young adults in the United States. J Clin Oncol. 2018;36(3):262-267.

22. Guo T, Eisele DW, Fakhry C. The potential impact of prophylactic human papillomavirus vaccination on oropharyngeal cancer. Cancer. 2016;122(15): 2313-2323. 10.1002/cncr.29992

23. Cornell JL, Halpern-Felsher BL. Adolescents tell us why teens have oral sex. J Adolesc Health. 2006;38(3):299-301. 10.1016/j.jadohealth.2005.04.015

24. Kirby DB. The impact of abstinence and comprehensive sex and STD/HIV education programs on adolescent sexual behavior. Sex Res Soc Pol 2008;5(3):18.

25. American Academy of Pediatrics, Committee on Public Education, American Academy of Child and Adolescent Psychiatry, American Psychological Association; Committee on Public Education. Sexuality, contraception, and the media. Pediatrics. 2001;107(1):191-194. 10.1542/peds.107.1.191

26. Planned Parenthood. Accessed Jun 10, 2020. 